\title{
HUBUNGAN PELAKSANAAN GOOD PHARMACY PRACTICE (GPP) DENGAN KEPUASAN KERJA APOTEKER DI APOTEK
}

\section{THE CORRELATION BETWEEN IMPLEMENTATION OF GOOD PHARMACY PRACTICE (GPP) AND JOB SATISFACTION OF PHARMACIST IN PHARMACIES}

\author{
PUTU EKA ARIMBAWA ${ }^{1 \bullet}$, DEWA AYU PUTU SATRYA DEWI ${ }^{1}$, I PUTU TANGKAS SUWANTARA ${ }^{2}$ \\ ${ }^{1}$ Prodi Farmasi Klinis, Institut Ilmu Kesehatan Medika Persada Bali, Denpasar-Bali \\ ${ }^{2}$ Akademi Farmasi Saraswati Denpasar, Jalan Kamboja no.11A, Denpasar
}

\begin{abstract}
Abstrak: Good pharmacy practice (GPP) merupakan standar untuk memastikan Apoteker dalam memberikan setiap pelayanan kefarmasian sehingga dapat menciptakan suatu kepuasan kerja. Tujuan penelitian adalah untuk mengetahui hubungan pelaksanaan good pharmacy practice (GPP) Dengan kepuasan kerja apoteker di apotek Kota Denpasar Penelitian ini dilakukan dengan desain survey cross sectional. Penelitian menggunakan kuesioner sebagai alat pengumpulan data. Teknik sampling yang digunakan adalah quota sampling. Jumlah sampel yang digunakan sebanyak 69 apoteker yang memiliki ijin praktek penanggung jawab di Kota Denpasar. Analisis data menggunakan uji statistika multivariat. Hasil penelitian menunjukkan bahwa terdapat hubungan yang tidak signifikan antara aspek kesejahteraan pasien $(\mathrm{p}=0.23)$ dan aspek kerjasama dengan dokter $(\mathrm{p}=0,07)$ terhadap kepuasan kerja. Untuk hubungan aspek manajemen $(\mathrm{p}=0.01)$ dan aspek kontribusi peran apoteker $(\mathrm{p}=0,001)$ memberikan hubungan yang signifikan dengan kepuasan kerja. Secara keselurahan pelaksanaan good pharmacy practice (GPP) dengan kepuasan kerja terdapat hubungan yang signifikan $(\mathrm{p}=0,04)$ dan memberikan pengaruh sebesar 1,65 kali $(\mathrm{OR}=1,65)$ terhadap kepuasan kerja apoteker di apotek.
\end{abstract}

Kata Kunci: Good Pharmacy Practice (GPP), Kepuasan kerja, Apoteker, Apotek

\begin{abstract}
Good pharmacy practice (GPP) is a standard for ensuring pharmacists in providing pharmaceutical services so as to create a job satisfaction. The objective of this research is to know the relation between implementation of good pharmacy practice (GPP) and job satisfaction of pharmacists in pharmacies. This research is cross-sectional study. The survey was conducted to 69 randomize selected pharmacists in Denpasar City. Obtained data is analyzed by multivariate statistical test. The result showed no statistically significant correlation between patient welfare aspect $(\mathrm{p}=0,23)$ and aspect of cooperation with physician $(\mathrm{p}=0,07)$ with job satisfaction. The relationship of management aspect $(\mathrm{p}=0.01)$ and job satisfaction $(\mathrm{p}=0,001)$ give significant relation with job satisfaction. The overall implementation of Good Pharmacy Practice (GPP) and job satisfaction has a significant relationship $(\mathrm{p}=0.04)$ and gives an effect of 1.65 times $(\mathrm{OR}=1.65)$ on the job satisfaction of pharmacists in pharmacies.
\end{abstract}

Keywords: Good Pharmacy Practice (GPP), Satisfaction Job, Pharmacist, Pharmacies

\section{PENDAHULUAN}

Pelayanan kefarmasian merupakan pelayanan kesehatan mempunyai peran penting khususnya pemahaman tentang obat. Apoteker sebagai bagian dari tenaga kesehatan mempunyai tugas dan tanggung jawab dalam mewujudkan pelayanan kefarmasian yang berkualitas. Untuk mencapai tujuan tersebut diperlukan pedoman bagi Apoteker yang dituliskan dalam bentuk good pharmacy practice (GPP) sebagai standar untuk memastikan Apoteker dalam memberikan setiap pelayanan kepada pasien agar memenuhi penerapan pharmaceutical care. GPP di apotek terdiri dari aspek kesejateraan pasien, aspek manajemen, aspek kontribusi peran apoteker, dan aspek kerjasama dengan dokter untuk peningkatan terapi pengobatan (International Pharmaceutical Federation. World Health Organization., 1996).

Pelaksanaan GPP di apotek masih belum dapat dilaksanakan dengan baik secara keseluruhan. Hal ini dibuktikan dari penelitian mengenai implementasi standar pelayanan kefarmasian di apotek Kabupaten Sleman tertinggi berkategori baik dengan persentase $65,71 \%$ (Karuniawati et al., 2015). Hasil penelitian lain menyatakan standar pelayanan kefarmasian di apotek Kota Yogyayakarta menurut apoteker

\footnotetext{
•e-mail korespondensi: eka apoteker@yahoo.co.id
} 
dengan katagori baik baru terlaksana 21\% (Atmini et al., 2011). Masih kurangnya pelaksanaan GPP di apotek ini membuktikan kinerja apoteker kurang baik.

Kepuasan kerja mempunyai peranan penting terhadap kinerja apoteker, ketika seorang apoteker merasakan kepuasan dalam bekerja maka apoteker tersebut akan berupaya semaksimal mungkin dengan segenap kemampuan yang dimiliki untuk menyelesaikan tugasnya, yang akhirnya akan menghasilkan pencapaian yang baik. Kepuasan kerja ini akan didapat apabila ada kesesuaian antara harapan pekerja dan kenyataan yang didapatkan ditempat bekerja (Jiang et al., 2012). Menurut hasil penelitian apoteker berada di apotek kurang dari $20 \mathrm{jam} / \mathrm{minggu}$ sehingga kinerja apoteker menjadi tidak maksimal dan kepuasan kerja tidak akan tercapai (Hermansyah $e t$ al., 2012). Sehingga dari uraian diatas dapat dilihat suatu permasalahan apakah penerapan GPP dapat meningkatkan kepuasan kerja apoteker di apotek Kota Denpasar.

\section{METODE PENELITIAN}

Penelitian ini merupakan penelitian korelasional. Penelitian ini dilakukan dengan desain survey cross sectional. Penelitian menggunakan kuesioner sebagai alat pengumpulan data. Teknik sampling yang digunakan adalah purposive sampling. Jumlah sampel yang digunakan sebanyak 69 apoteker yang memiliki ijin praktek penanggung jawab di apotek Kota Denpasar dari 241 apoteker penanggung jawab.

Perhitungan sampel yang digunakan adalah sebagai berikut:

$$
\begin{aligned}
\mathrm{n}= & \frac{z_{1-\alpha / 2}^{2} \mathrm{P}(1-\mathrm{P}) \mathrm{N}}{\mathrm{d}^{2}(\mathrm{~N}-1)+z_{1-\alpha / 2}^{2} \mathrm{P}(1-\mathrm{P})} \\
& =\frac{(0,95)^{2} 0,5(1-0,5) 241}{0,1^{2}(241)+(0,95)^{2} 0,5(1-0,5)} \\
= & 69 \text { Sampel }
\end{aligned}
$$

Keterangan:

$$
\begin{array}{ll}
\mathrm{n} & =\text { Sampel } \\
\mathrm{P} & =\text { Peluang } \\
\mathrm{N} & =\text { Populasi } \\
\mathrm{d} & =\text { Limit error atau presisi absolut } \\
\mathrm{Z}_{1-\alpha / 2}^{2} & =\text { Derajat kepercayaan }
\end{array}
$$

Analisis data menggunakan uji multivariat untuk melihat hubungan antara pelaksanaan good pharmacy practice (GPP) dengan kepuasan kerja apoteker.

\section{HASIL DAN PEMBAHASAN}

Karakteristik sampel. Hubungan karakteristik sampel seperti umur, jenis Kelamin, pekerjaan selain apoteker, status pernikahan, kepuasan kerja, aspek kesejahteraan pasien, aspek manajemen, aspek kontribusi peran apoteker, dan aspek kerjasama dengan dokter terhadap kepuasan kerja dilihat pada tabel 1 .

Uji multivariat hubungan aspek-aspek pelaksanaan GPP dengan kepuasan kerja apoteker. Hasil uji multivariat untuk aspek kesejahteraan pasien, manajemen, kontribusi apoteker, kerjasama dengan dokter terhadap kepuasan kerja dapat dilihat pada tabel 2.

Hubungan aspek kesejahteraan pasien
terhadap kepuasan kerja. Hubungan aspek
kesejahteraan pasien dengan kepuasan kerja
menunjukan hasil yang tidak signifikan (p=0,23).
Kesejahteraan pasien merupakan prioritas utama
yang harus dilaksanakan oleh semua petugas
kesehatan terutama oleh apoteker. Fokus praktek
seorang apoteker dalam profesionalitas adalah
sesuai dengan kebutuhan pasien tanpa
mengharapkan imbalan sehingga kesejahteraan
pasien merupakan kewajiban bagi seorang
apoteker dalam melakukan praktek kefarmasian
(Chisholm et al., 2006).


Tabel 1. Hubungan karakteristik sampel terhadap kepuasan kerja

\begin{tabular}{|c|c|c|}
\hline $\begin{array}{c}\text { Karakterisitik } \\
\text { Sampel }\end{array}$ & $\mathbf{f}(\%)$ & $p$-value \\
\hline $\begin{array}{l}\text { Umur } \\
\qquad 27 \text { tahun } \\
>27 \text { tahun }\end{array}$ & $\begin{array}{l}37(53,6) \\
32(46,4)\end{array}$ & 0.59 \\
\hline $\begin{array}{l}\text { Jenis Kelamin } \\
\text { Laki-laki } \\
\text { Perempuan } \\
\end{array}$ & $\begin{array}{l}24(34,8) \\
45(65,2)\end{array}$ & 0.98 \\
\hline $\begin{array}{c}\text { Pekerjaan Selain Apoteker } \\
\text { Ada pekerjaan } \\
\text { Tidak Ada } \\
\end{array}$ & $\begin{array}{l}23(33,3) \\
46(66,7)\end{array}$ & 0.86 \\
\hline $\begin{array}{l}\text { Status Pernikahan } \\
\text { Menikah } \\
\text { Belum Menikah }\end{array}$ & $\begin{array}{l}41(59,4) \\
28(40,6)\end{array}$ & 0.78 \\
\hline $\begin{array}{l}\text { Aspek kesejahteraan pasien } \\
\text { Baik } \\
\text { Kurang baik }\end{array}$ & $\begin{array}{l}33(47,8) \\
36(52,2)\end{array}$ & 0.0001 \\
\hline $\begin{array}{l}\text { Aspek Manajemen } \\
\text { Baik } \\
\text { Kurang baik }\end{array}$ & $\begin{array}{l}35(50,7) \\
34(49,3)\end{array}$ & 0.0001 \\
\hline $\begin{array}{l}\text { Aspek Kontribusi Peran } \\
\text { Apoteker } \\
\text { Baik } \\
\text { Kurang Baik }\end{array}$ & $\begin{array}{l}36(52,2) \\
33(47,8)\end{array}$ & 0.0001 \\
\hline $\begin{array}{l}\text { Aspek Kerjasama dengan } \\
\text { Dokter } \\
\text { Baik } \\
\text { Kurang baik }\end{array}$ & $\begin{array}{l}34(49,3) \\
35(50,7)\end{array}$ & 0.0001 \\
\hline
\end{tabular}

Hubungan Aspek manajemen terhadap Kepuasan kerja. Hubungan aspek manajemen dengan kepuasan kerja menunjukkan hubungan yang signifikan $(\mathrm{p}=0,01)$. Sistem manajemen yang efektif adalah sebuah proses yang membantu organisasi untuk mencapai tujuan jangka panjang dan jangka pendeknya, Manajemen kinerja merupakan alat mencapai sukses, yang dibutuhkan oleh organisasi, manajer dan karyawan untuk mencapai sukses (Shobikin, 2012). Sehingga dapat disimpulkan sistem manajemen yang profesional akan menciptakan suatu sistem kerja yang teratur dan nantinya akan berdampak pada kinerja apoteker yang optimal.

Hubungan aspek kontribusi peran apoteker terhadap kepuasan kerja. Hubungan aspek kontribusi peran apoteker dengan kepuasan kerja menunjukkan hasil yang signifikan $(\mathrm{p}=0,001)$. Kontribusi apoteker berkaitan dengan kompetesi profesionalisme pelayanan kefarmasian yang dimilikinya.

Tabel 2. Uji multivariat aspek-aspek pelaksanaan GPP dengan kepuasan kerja apoteker di apotek kota Denpasar

\begin{tabular}{lccc}
\hline \multirow{2}{*}{ Aspek Good Pharmacy Practice } & p-value & \multicolumn{2}{c}{ CI 95\% } \\
\cline { 3 - 4 } & & Batas bawah & Batas atas \\
\hline Aspek Kesejahteraan Pasien & 0.23 & 0,52 & 13,97 \\
Aspek Manajemen & 0.01 & 1,43 & 19,86 \\
Aspek Kontribusi Apoteker & 0.001 & 2.68 & 38.52 \\
Aspek Kerjasama dengan Dokter & 0.07 & 0.824 & 18.25 \\
\hline
\end{tabular}

CI* Confidence Interval 95\%

Kompetensi profesional merupakan kemampuan yang berkenaan dengan penguasaan suatu ilmu tertentu. Suatu pekerjaan yang bersifat professional memerlukan beberapa bidang ilmu khusus dipelajari dan kemudian diaplikasikan bagi kepentingan umum. Sehingga pekerjaan professional berbeda dengan pekerjaan lainnya karena suatu profesi memerlukan kemampuan dan keahlian khusus dalam melaksanakan profesinya. Semakin tinggi dan berbeda kompetensi yang dimiliki seseorang maka kepuasan kerja seseorang juga semakin baik (Sari, 2013).

\section{Hubungan aspek kerjasama dengan dokter terhadap kepuasan kerja}

Hubungan aspek kerjasama dengan dokter terhadap kepuasan kerja menunjukan hasil yang tidak signifikan $(\mathrm{p}=0,07)$. Kinerja seseorang ditentukan oleh faktor kepribadian. Kepribadian merupakan bagaimana individu tampil dan menimbulkan kesan bagi individu lain atau suatu organisasi yang dinamis yang menentukan tingkah laku dan pemikiran individu secara khas (Afidah and Pratiwi, 2005). Sehingga kepuasan kerja apoteker yang baik tidak berhubungan dengan kerjasama, melainkan bagaimana kepribadian individu apoteker tersebut menyesuaikan diri dengan lingkungan tempat melakukan suatu praktek kefarmasian. 
Uji multivariate hubungan pelaksanaan GPP dengan kepuasan kerja apoteker di apotek. Secara keseluruhan hubungan pelaksanaan GPP dengan kepuasan kerja apoteker dapat dilihat pada tabel 3.

Tabel 3. Pelaksanaan GPP dengan kepuasan kerja apoteker

\begin{tabular}{lcc}
\hline \multicolumn{2}{c}{ Kepuasan kerja } \\
\hline \multirow{2}{*}{$\begin{array}{c}p \text { value } \\
\text { GPP }\end{array}$} & 0.04 & OR \\
\cline { 2 - 3 } *OR=Ods Ratio & & 1.65 \\
\hline
\end{tabular}

Pelaksanaan good pharmacy practice secara keseluruhan memberikan hubungan yang siginifikan $(\mathrm{p}=0,04)$ dan memberikan pengaruh sebesar 1,65 kali $(\mathrm{OR}=1,65)$ terhadap kepuasan kerja. Pelaksanaan GPP merupakan suatu standar yang harus diterapkan di apotek. Penerapan standar GPP akan membuat jaminan keamanan bagi pelaksana pelayanan kefarmasian. Jaminan keamanan akan sangat mempengaruhi timbulnya rasa puas dalam bekerja, karena apabila sudah terciptanya keamanan dan kenyamanan dalam bekerja maka kepuasan kerja akan menjadi lebih baik (Akmal et al, 2013).

\section{SIMPULAN}

Pelaksanaan GPP di apotek dapat memberikan 1,65 kali kepuasan kerja apoteker. Untuk itu pelaksanaan GPP di apotek sangat perlu diterapkan sebagai standar dari pelaksanaan pelayanan kefarmasian, sehingga tujuan penerapan pharmaceutical care dapat tercapai.

\section{UCAPAN TERIMA KASIH}

Ucapan terima kasih diberikan semua pihak yang membantu dalam penyelesaian jurnal ini terutama kepada apoteker Kota Denpasar yang sudah berpatisipasi dalam penelitian ini.

\section{DAFTAR PUSTAKA}

Afidah, N. and Pratiwi, A. 2005. Hubungan antara Tipe Kepribadian Dengan Kinerja Perawat Di Rumah Sakit PKU Muhammadiyah Surakarta, pp. 196-205.
Akmal D., Syahrul, dan Aulia. 2013. Analisis Faktor-Faktor Yang Mempengaruhi Kepuasan Kerja Apoteker Yang Bekerja Di Apotek Di Kota Padang. Jurnal Sains dan Teknologi Farmasi, Vol. 18, No.1, 2013, halaman 1-8, 20(3).

Atmini, K. D., Gandjar, I. G. and Purnomo, A. 2011. Jurnal Manajemen dan Pelayanan Farmasi Vol. 1 No. 1, Maret 2011. Jurnal Manajemen dan Pelayanan Farmasi, 1(1), pp. 49-55.

Chisholm, M. A., Cobb, H., \& Duke, L. 2006. Development of an instrument to measure professionalism. American Journal of Pharmaceutical Education, 70(4). doi: 10.5688/aj700485.

Hermansyah, A., Sukorini, A. I., \& Setiawan, C. D. 2012. The conflicts between professional and non professional work of community pharmacists in Indonesia. Pharmacy practice, 10(1), pp. 33-9. doi: 10.4321/S188636552012000100006 .

International Pharmaceutical Federation. World Health Organization. 1996. Good Pharmacy Practice in community and hospital pharmacy settings.

Jiang, J. J., Klein, G. and Saunders, C. 2012. Discrepancy Theory Models of Satisfaction in IS Research. Information Systems Theory, 28, pp. 355-381. doi: 10.1007/978-1-4419-6108-2.

Karuniawati, H., Ikawati, Z. and Gofir, A. 2015. Jurnal Manajemen dan Pelayanan Farmasi (JMPF) Journal of Management and Pharmacy Practice. Jurnal Manajemen dan Pelayanan Farmasi, 5(1), pp. 14-21. Available at: http://jmpf.farmasi.ugm.ac.id/index.php/1/arti cle/view/94.

Sari, F. M. 2013. Pengaruh Kompetensi Dan Lingkungan Kerja Terhadap Kepuasan Kerja dan Kinerja Guru di SD Negeri Kecamatan Gondang Mojokerto, 9(2).

Shobikin .2012. Pengaruh Manajemen Kinerja Dan Lingkungan Kerja Terhadap Kepuasan Kerja Serta Pengembangan Karier Di Kantor Kelurahan Banaran Kecamatan Babat Kabupaten Lamongan. Media Mahardhika, 11(1), pp. 39-61. 
Lampiran Kuesioner

\section{KUESIONER}

BERIKANLAH TANDA V PADA KOLOM YANG TERSEDIA

Jenis kelamin Laki-laki

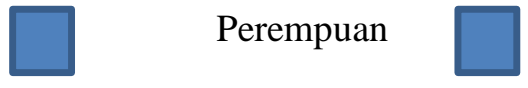

Pekerjaan selain sebagai apoteker di apotek tempat melakukan praktek profesi

Pengusaha

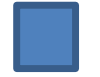

PNS/BUMN

Lainya .(Sebutkan)
Karyawan swasta

Tidak ada

Kepemilikan saham di tempat apotek bekerja

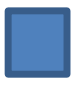

Tidak ada

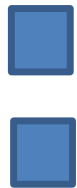

$51-80 \%$

$1-20 \%$

$81-100 \%$

$21-50 \%$

Umur dalam tahun $=$

Status Pernikahan

Sudah menikah

Belum Menikah 


\section{KUESIONER GOOD PHARMACY PRACTICE}

\begin{tabular}{|c|c|c|c|c|c|c|c|c|}
\hline \multicolumn{4}{|c|}{ KENYATAAN } & \multirow{2}{*}{$\begin{array}{l}\text { GOOD PHARMACY PRACTICE } \\
\text { (GPP) }\end{array}$} & \multicolumn{4}{|c|}{ HARAPAN } \\
\hline $\begin{array}{c}\text { Tidak } \\
\text { baik }\end{array}$ & $\begin{array}{c}\text { Kurang } \\
\text { baik }\end{array}$ & Baik & $\begin{array}{c}\text { Sangat } \\
\text { baik }\end{array}$ & & $\begin{array}{l}\text { Tidak } \\
\text { setuju }\end{array}$ & $\begin{array}{l}\text { Kurang } \\
\text { setuju }\end{array}$ & Setuju & $\begin{array}{l}\text { Sangat } \\
\text { setuju }\end{array}$ \\
\hline & & & & $\begin{array}{l}\text { Apoteker berinteraksi dengan } \\
\text { pasien dan memperlakukan } \\
\text { dengan rasa hormat yang } \\
\text { sama tanpa melihat latar } \\
\text { belakang social serta } \\
\text { kemampuan membayar }\end{array}$ & & & & \\
\hline & & & & $\begin{array}{l}\text { Apoteker memberikan } \\
\text { alternatif pilihan untuk } \\
\text { pemenuhan kebutuhan pasien } \\
\text { sesuai dengan kemampuan } \\
\text { membayar }\end{array}$ & & & & \\
\hline & & & & $\begin{array}{l}\text { Dalam hal obat yang tidak } \\
\text { tersedia, pemenuhan } \\
\text { kebutuhan obat di usahakan } \\
\text { dari tempat lain tanpa biaya } \\
\text { tambahan }\end{array}$ & & & & \\
\hline & & & & $\begin{array}{l}\text { Apoteker membangun } \\
\text { hubungan professional dengan } \\
\text { dokter untuk mendapatkan } \\
\text { terapi yang efektif kepada } \\
\text { pasien }\end{array}$ & & & & \\
\hline & & & & $\begin{array}{l}\text { Apoteker melakukan } \\
\text { konsultasi dan kerjasama } \\
\text { dengan apoteker/apotek } \\
\text { lainya dalam memberikan } \\
\text { terapi kepada pasien }\end{array}$ & & & & \\
\hline & & & & $\begin{array}{l}\text { Pengelolaan sediaan farmasi } \\
\text { melalui perencanaan yang baik } \\
\text { didukung kartu stock dan buku } \\
\text { defecta }\end{array}$ & & & & \\
\hline & & & & $\begin{array}{l}\text { Pengadaan sediaan farmasi } \\
\text { melalui jalur resmi sesuai } \\
\text { peraturan undang-undang } \\
\text { yang berlaku }\end{array}$ & & & & \\
\hline & & & & $\begin{array}{l}\text { Penyediaan sediaan farmasi } \\
\text { didukung oleh fasiltas yang } \\
\text { lengkap di apotek }\end{array}$ & & & & \\
\hline & & & & $\begin{array}{l}\text { Membuat penandaan bagi } \\
\text { obat-obat yang } 1 \text { tahun } \\
\text { terakhir akan kadarluarsa } \\
\text { (Expired date) dan } \\
\text { memisahkan obat-obat yang } \\
\text { kadarluarsa }\end{array}$ & & & & \\
\hline
\end{tabular}




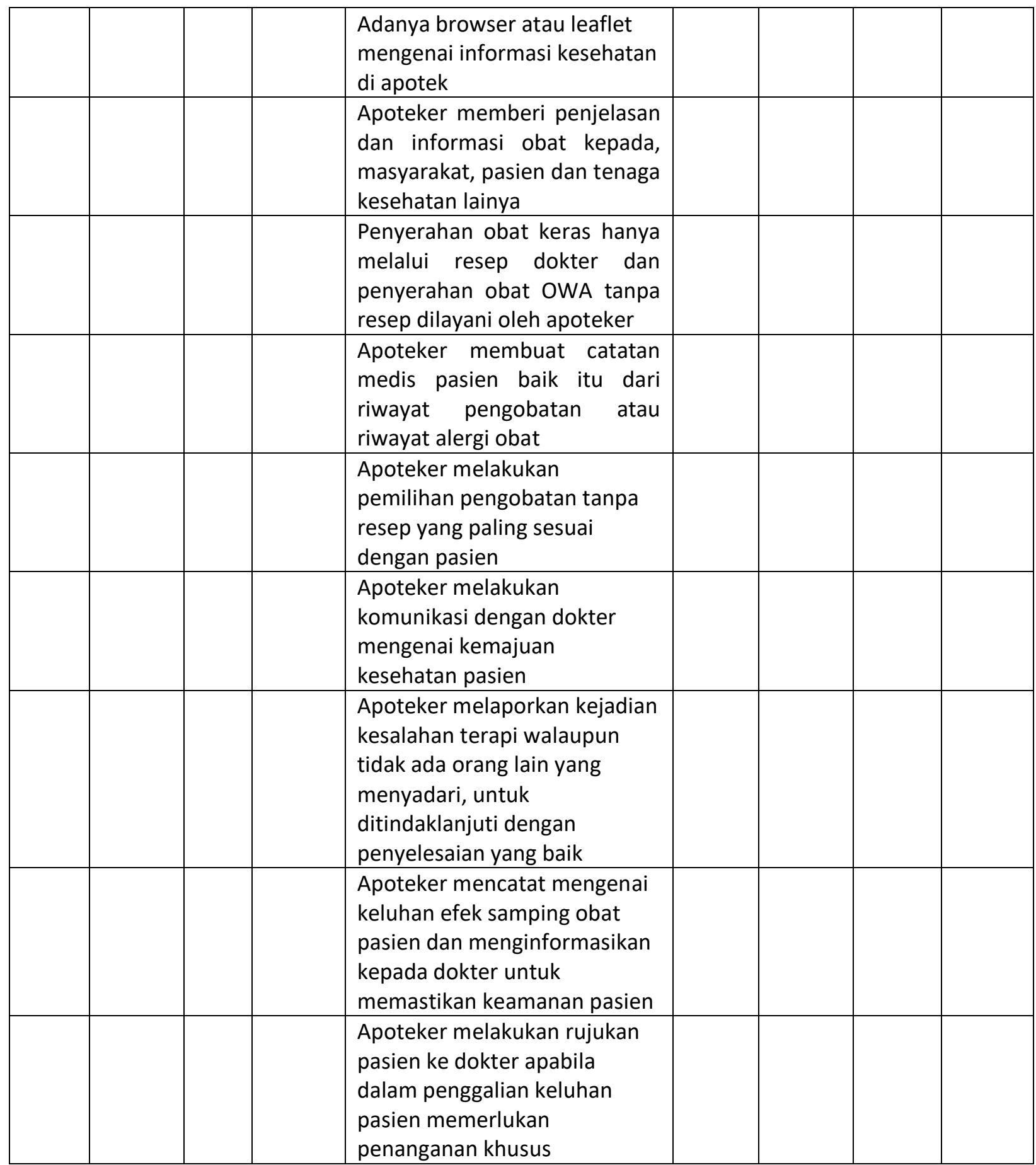

